\title{
Terminology and Toothbrushes
}

\author{
Kleanthes Grohmann, reply by Evelina Leivada
}

In response to "Misused Terms in Linguistics" (Vol. 5, No. 2).

To the editors:

Although Evelina Leivada raises a number of important issues concerning terminological (mis)use and confusion in linguistic theorizing, her introductory quote should not be taken too literally. It may indeed be the case that "linguists 'would rather share each other's toothbrush than each other's terminology"'1-but so what? There are many situations that might prompt the sharing of toothbrushes, such as an unexpected stayover, a group of people stuck in the middle of nowhere with only a single toothbrush, and so on. In all such situations, there would arguably be more pressing concerns than dental hygiene. And sharing toothbrushes is not a problem if you disinfect the toothbrush first. It doesn't take much time or effort to prepare one's toothbrush for someone else's use. And this is where terminological conundrums in linguistic theorizing enter.

Terminology matters. And, indeed, it is everywhere, ranging from apparently banal such as, say, "bilingualism," 2 to the specific terms that are "misused," as Leivada writes, and even to linguistics as a whole-take, for example, recent reflections by Martin Haspelmath. ${ }^{3}$ But let me start from the end of her essay. Leivada suggests that "terminological clarity matters" because a "senior linguist" assumes that "UG is simply a repository of linguistic primitives that can be disconnected from human biology." Leivada strongly disagrees with this statement and employs it as an example of the misuse of linguistic terminology.

This scenario is a great example of a much more serious matter, which Leivada only mentions in passing. While she makes several statements about "the biological plausibility of an innate endowment for language," what is completely missing from Leivada's essay is any discussion of biolinguistics as the relevant field of study. By way of a partial disclaimer, I should add that I recently contributed to a survey of biolinguistics and its relevance for cognitive linguistics at large. ${ }^{4}$ Leivada is heavily involved in this research agenda herself, as one of the initial team members and as associate editor of the free, open-access journal Biolinguistics, which I cofounded. ${ }^{5}$

The relevance of biolinguistics is that not every linguist subscribes to it as the designated research program. The senior linguist mentioned by Leivada is presumably one such researcher. Many linguists do not assume a biological point of view, or at least not the linguist's need to contribute to it. What makes matters worse, and I say this as a generative biolinguist, is that not every linguist is a generative linguist. And what Leivada really worries about is terminology used and misused by generative linguists themselves-mostly, though not exclusively, within the Chomskyan conception of linguistic minimalism. ${ }^{6}$

Here one can detect a category mistake. Some of the terms predate generative linguistics and were adopted or extended, such as "features." Others were co-opted and adapted, such as "universal grammar." Yet others were introduced by it, as in "faculty of language in the narrow sense." Still other terms enjoy heavy engagement outside linguistics, such as "bilingual advantage." Haspelmath is a general linguist who tries to put some order in terminology and definitions for a wider readership, ${ }^{7}$ though frankly his attempts often seem to include all linguists except generativists.

Biolinguistics and generative grammar, or even linguistic minimalism, are not synonyms. Biolinguistics does not require subscribing to the minimalist program, nor can it be equated with generative grammar as a whole. ${ }^{8}$ There are minimalist syntacticians who care little for essentially biolinguistic issues. There are also generative linguists both within and outside minimalism who do not, explicitly so, even if they assume a language faculty. Many linguists concerned with essentially biolinguistic issues even use the term "biolinguistics" in their work, but are anything but generative in their theoretical persuasion, from functional to other cognitive approaches. ${ }^{9}$

It is not immediately clear whether sharing terminology across disciplines, "such as other parts of psychology, biology, and neuroscience," as Leivada suggests, is really more important than sharing terminology across the subdisciplines of linguistics. If one's response is, "Yes, it is," then we might perpetuate the multi-forked approach to 
language science. One route is nativist and generative, perhaps involving minimalist biolinguists pursuing their current research agenda, either alone-biolinguistics in the weak sense-or teaming up across disciplines-possibly biolinguistics in the strong sense. In that case, none of the terminological conundrums identified by Leivada really matter. The relevant players will work with theiror Leivada's?-understanding and pass it on to colleagues and collaborators from different fields. Other linguists will remain at a loss, as will anyone else who does not subscribe to these understandings.

Alternatively, linguists might define, redefine, or establish a common definition of all of these terms in a way that a larger group of linguists can agree with. But this means preparing terminology within the large, multifaceted field of language science. There is a rich tradition of adopting, adapting, co-opting, and (mis)using terminology in recent history, ranging from structuralism to generativism to the so-called linguistic wars and beyond..$^{10}$ To experience just some highlights, ${ }^{11}$ read up on the nonsensical nature-versus-nurture debate, ${ }^{12}$ apparently false dichotomies, ${ }^{13}$ and discussion concerning the granularity mismatch problem. ${ }^{14}$

There is definitely room for improvement in the current state of linguistics, how languages can be studied, and why linguists should care about diversity in approaches and outlooks. But we should also try to discern who our readers are and cater to them. If we only talk to generative linguists and biolinguists, we should say so from the outset and avoid referring to linguistics as a whole, or at least not be surprised if others express disapproval. If we want to include all kinds of linguistics, we may want to start by putting the issues, notions, and terms in a wider perspective.

We should also clarify why we would want to bring this discussion out into the open. Is the discussed being conducted for the benefit of that senior linguist and colleagues of a similar mind? At this point, there are senior linguists who talk publicly about biolinguists on the one hand and philologists on the other. Or, put differently, they talk about a distinction between "linguistics (or biolinguistics, with focus on [the faculty of language]) and languistics (with focus on ... 'language data')-a state of affairs reminiscent of the distinction between biolinguistics in the strong and biolinguistics in the weak sense."15 Is a terminological clearing intended for linguistics thus conceived? Or is it in order to talk to neighboring fields, such as psychology, biology, and neuroscience? Does every linguist want to do that, to begin with? Let's just say that the target audience of Leivada's piece would be, roughly, nativist linguists who appreciate and perhaps to some extent follow Noam Chomsky's generative approach from the past seven decades.

Chomsky's usage was, from the very beginning, different from that other "philosophical grammar (or general grammar, or universal grammar)."16 From his earliest writings, it was quite clear that, for generative linguists, "Universal Grammar (UG) is the source of our innate ability to acquire and use a natural language," as Leivada put it. UG is neither a language nor a set of grammatical properties. It is, in Chomsky's words, "the theory of the genetically based language faculty."17 $\mathrm{He}$ introduced this conception of UG in the $1960 \mathrm{~s} .{ }^{18}$ He later wrote that the "principles of universal grammar are exceptionless, because they constitute the language faculty itself, a framework for any particular human language, the basis for the acquisition of language." In the context of the principles and parameters (P\&P) theory, "the principles of universal grammar have certain parameters, which can be fixed by experience," so that

we may think of the language faculty as a complex and intricate network of some sort associated with a switch box consisting of an array of switches that can be in one of two positions.

Thus, "the fixed network is the system of principles of universal grammar; the switches are the parameters to be fixed by experience."19

This short passage mentions several of Leivada's points of contention, including that "principles of universal grammar are part of the fixed structure of the mind/ brain" ${ }^{20}$ and that "the language faculty, a physical mechanism ... has certain definite properties ... that the theory of universal grammar seeks to formulate and describe." ${ }^{21}$ The technical aspects of the P\&P approach may have changed, as Leivada notes, but is there really arbitrary meaning and fluidity in its present-day usage and adaptations? Not every linguist, generative or otherwise, joined Chomsky and his followers on the explicit biolinguistic journey, or on the reduction of the language faculty, which eventually led to the FLB/FLN distinction. ${ }^{22}$ This may also hold be true of the senior linguist for whom Leivada created her list.

The Chomsky quotes above are taken from the same book. Elsewhere he writes:

We should be concerned to abstract from successful grammars and successful theories those more general properties that account for their success, and to develop [universal grammar] as a theory of these abstract properties, which might be realized in a variety of different ways. ${ }^{23}$

And,

The theory of UG must meet two obvious conditions. On the one hand, it must be compatible with the diversity of existing (indeed, possible) grammars. At the same time, UG must be sufficiently constrained and restrictive in the options it permits so as to account for the fact that each of these grammars develops in the mind on the basis of quite limited evidence. ${ }^{24}$ 
I would think that all generative linguists subscribe to these descriptions, even today, in one form or another.

Things might get murkier when talking about "the principles of phrase structure, binding theory, and other subsystems of universal grammar," 25 where "one component of universal grammar is case theory [emphasis omitted], a system that stands alongside of binding theory and other subsystems of the language faculty." ${ }^{26}$ This refers back to the classically modular conception of the language faculty in a complex P\&P architecture. Once more, Leivada's senior linguist might have followed Chomsky all the way through decades of generative theorizing-but then decided to remain in a general P\&P approach. If this was indeed the case, the senior linguist is far from alone.

In a larger sense, I do agree that there is a terminological jungle. But this is not restricted to the biolinguistics research agenda, which Leivada did not mention by name, or even generative linguistics in general, which she did, though perhaps she did not make it sufficiently clear. Looking at the selection Leivada provided, it is not immediately clear that avoiding misuses will really help linguistics as a whole improve its visibility in neighboring fields. Misconceptions and mistrust already exist and the so-called linguistic wars did their part without the need to worry about terminology. Before linguists can talk about improved visibility, we should be clear about our field, or rather fields, of study in the first place. That means getting Leivada's senior linguist onto the same page as, say, Haspelmath, macro- and micro-cognitive linguists, ${ }^{27}$ and many others.

In the meantime, I will be eagerly awaiting Leivada's next installment of abused, confused, and misused terminological notions in scientific language research. If the next selection is as sharp as this one, it will be indispensable for many us.

\section{Kleanthes Grohmann}

\section{Evelina Leivada replies:}

In his letter to the editors, Kleanthes Grohmann offers a balanced discussion of what my essay did and did not do. His suggestions about the latter provide a great opportunity to expand on some important issues, so I will focus on these and address the questions he raises.

According to Grohmann, an important omission in my essay is any reference to biolinguistics as the relevant field of study for some of the terms I discussed. He is right in observing so, and there is a reason behind my decision. First, let me highlight that my essay lists half a dozen references that mention biolinguistics and discuss core aspects of the biolinguistic enterprise. If the term itself is absent from the discussion, this is because I purposely tried to maximize relatability to the main message of my essay. One point of criticism I repeatedly received when presenting this work in a way that featured the biolinguistic approach was why does this matter for us? This biolinguistic approach does not have a focus on the main theoretical interests we generative linguists have. It seems to me that the problem is not that "many linguists do not assume a biological point of view, or at least not the linguist's need to contribute to it," as Grohmann writes. Instead it is that many (generative) linguists who do work in biolinguistics-for example, discussing the lexicon, working with universal principles, evoking primitives they allocate to Universal Grammar, using brain imaging techniques to approach issues about language, etc.-explicitly distance themselves from it. I fully agree with Grohmann that biolinguistics and generative grammar are not synonymous. But I think this claim is not directly related to my essay, because I did not write an essay for generative linguists. The terms I discussed are not used inconsistently or incorrectly only by generative linguists or biolinguists or cognitive linguists; they are used inconsistently or incorrectly across frameworks. ${ }^{28}$

Grohmann also identifies a potential source of confusion that may arise from my discussion. He observes that it is not clear whether sharing terminology across disciplines (e.g., linguistics, other branches of psychology, biology, neuroscience) is more important than sharing terminology across subdisciplines of linguistics. I think this question shows how easy it is to mix two critical problems, both of which occur within and across linguistic frameworks: (i) the inconsistent use of certain terms and (ii) the fact that, in some cases, terms are ascribed definitions that defy well-known theses of other disciplines. To offer an example of the latter, if a linguist argues that Universal Grammar is genetically transmitted from parents to children in the form of a language gene, a biologist would probably reply that there is no specific gene dedicated to language, but many: some doing $\mathrm{X}$ in developmental stage $\mathrm{A}$ and $\mathrm{Y}$ in developmental stage $\mathrm{B}$. These two problems go hand in hand. Asking which is more important is not the right way to go about them, because their solutions are intertwined: Getting rid of definitions that defy what a biologist would consider common sense-i.e., problem (ii)-also addresses problem (i) by means of reducing the alternative definitions that are associated with a polysemous term.

The third question Grohmann raises asks why we would want to bring this discussion about terminological clarity out into the open and whether doing so is to the benefit of senior linguists like the one I mention in the anecdote that closes my essay. For me, the answer does not have anything to do with specific people. It has to do with the status of the field. Discussing matters of terminology may dispel ambiguities and bring to light incorrect uses of certain terms. It may show that some definitions are more sustainable and some terms more ambiguous than others. These are important pieces of knowledge, or so psychologists think. ${ }^{29}$ Precisely because the focus is on the field 
and not specific scholars, I am not sure why Grohmann does not exclusively emphasize that terminological clarity matters for the coherence of the field itself; instead he focuses also on how I suggest "that 'terminological clarity matters' because a 'senior linguist' assumes that ' $U G$ is simply a repository of linguistic primitives that can be disconnected from human biology." The anecdote at the end of my essay is merely an example of the kind of disruption that communication may face, even among linguists who work with the same notions and admire each other's work (admittedly, I can only be sure about my admiration of the other person's work). It is just one example among the many, and terminological clarity matters in ways that go far beyond this incident. I briefly talk about these ways in my reply to Juan Uriagereka's letter, but Grohmann's letter gives me a useful opportunity to mention them again. Linguistics is a small field. Diminished internal coherence translates to poor external visibility, to few or no grants in major research calls (with all the consequences this may have for graduate fellowships, at least in Europe), and to a loss of valuable opportunities for communication and collaboration with neighboring fields. In sum, terminological incoherence matters in light of the many challenges the discipline faces as a consequence.

These challenges are real in present-day linguistics, which relates to Grohmann's inquiry about whether there really is inconsistency in the present-day usage of some of the terms of I discussed. The answer is yes. I offer concrete examples in my reply to Anna Maria Di Sciullo's letter.

Overall, I agree with all the other insights that Grohmann offers in his letter, except just one thing. He recommends to discern who our readers are and cater to them. I disagree for reasons I only hinted at in my essay but will try to properly justify in the rest of this reply. I think all colleagues will agree that linguists have the responsibility to articulate robust and cohesive theories about their objects of study. In my opinion, this responsibility does not change depending on who sits in the audience, because theories should not be presented in substantially different ways depending on who is listening. Different sources of evidence in favor of a theory can of course be adduced, but the burden of terminological and conceptual clarity should remain unaltered regardless of the audience-regardless of whether the audience includes a biologist, who can easily pick holes in an unsustainable definition of Universal Grammar, or not. This brings me to Grohmann's next suggestion. If one wishes to embed their "issues, notions, and terms in a wider perspective," as Grohmann puts it, this is fine. If they do not, this is fine too. Concerns arise only when a theory is ridden with inconsistencies that weaken its defensibility. Adopting a wider perspective to cater to different audiences should be a matter of choice. Adopting a perspective that refrains from attaching unsustainable definitions to basic terms should be a minimum requisite in any scientific endeavor. Moreover, since we have no control over who will be influenced by our theories and when, we may shift our attention to more pressing issues, such as the need to register ambiguities that surround the use of other terms.

Grohmann is right to view a second installment of misused, polysemous, and inconsistently used terms as indispensable for the field. For this reason, I refer the interested reader to the excellent commentary by JoséLuis Mendívil-Giró on language evolution, and I hope more colleagues will join forces in this initiative.

\section{Kleanthes Grohmann is Professor of Biolinguistics and Director of the CAT lab at the University of Cyprus.}

\section{Evelina Leivada is a psycholinguist at the Universitat} Rovira $i$ Virgili in Tarragona, Spain.

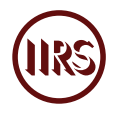

1. In Leivada's essay, the quote is credited to Eörs Szathmáry, an evolutionary biologist, conveyed in Remi van Trijp, "Use Your Own Toothbrush," Essays in Linguistics (blog). Incidentally, Szathmáry's field has its own terminological and explanatory issues that also touch on relevance for language.

2. Tanja Kupisch and Jason Rothman, "Terminology Matters! Why Difference Is Not Incompleteness and How Early Child Bilinguals Are Heritage Speakers," International Journal of Bilingualism 22, no. 5 (2018): 564-82, doi:10.1177/1367006916654355.

3. See, for example, Martin Haspelmath, Diversity Linguistics Comment (blog), and various papers posted and discussed there.

4. Kleanthes Grohmann and Maria Kambanaros, "Foundational Issues in Biolinguistics," in The Routledge Handbook of Cognitive Linguistics, eds. John Taylor and $\mathrm{Xu}$ Wen (London: Routledge, forthcoming).

5. Biolinguistics journal.

6. This refers to Noam Chomsky, The Minimalist Program (Cambridge, MA: MIT Press, 1995), and so much work since. For a comprehensive textbook introduction, see Norbert Hornstein, Jairo Nunes, and Kleanthes Grohmann, Understanding Minimalism (Cambridge: Cambridge University Press, 2005). See also the volume in preparation by Kleanthes Grohmann and Evelina Leivada (eds.), The Cambridge Handbook of Minimalism (Cambridge: Cambridge University Press, forthcoming).

7. Haspelmath, Diversity Linguistics Comment (blog).

8. See e.g., Cedric Boeckx, "Biolinguistics: Fact, Fiction, and Forecast," Biolinguistics 7 (2013): 316-28, responding to Ray Jackendoff, "What Is the Human Language Faculty? Two Views," Language 87 (2011): 586-624, doi:10.1353/ lan.2011.0063.

9. For more discussion and references, see Grohmann and 
Kambanaros, "Foundational Issues in Biolinguistics."

10. A quarter of a century ago, this was tackled by Frederick Newmeyer, Generative Linguistics: A Historical Perspective (New York: Routledge, 1996). There are some more recent reflections out there as well.

11. There is more to be found in Grohmann and Kambanaros, "Foundational Issues in Biolinguistics."

12. A classic text would be Language and Learning: The Debate between Jean Piaget and Noam Chomsky, ed. Massimo Piattelli-Palmarini (Cambridge MA: Harvard University Press, 1980). For a recent perspective, see Stephen Crain and Paul Pietroski, "Nature, Nurture, and Universal Grammar," Linguistics and Philosophy 24 (2001): 139-86, doi:10.1023/a:1005694100138.

13. See Ronald Langacker, Foundations of Cognitive Grammar, vol. 1 (Stanford, CA: Stanford University Press, 1987).

14. For starters, see David Poeppel and David Embick, "Defining the Relation between Linguistics and Neuroscience," in Twenty-First Century Psycholinguistics: Four Cornerstones, ed. Anne Cutler (Mahwah, NJ: Lawrence Erlbaum Associates, 2005), 103-18.

15. The quote is from Evelina Leivada, "The Nature and Limits of Variation across Languages and Pathologies" (PhD dissertation, University of Barcelona, 2015), 94. She refers to Norbert Hornstein, "LSA Summer Camp," Faculty of Language (blog), July 24, 2003, on languistics/linguistics, and Cedric Boeckx and Kleanthes Grohmann, "The Biolinguistics Manifesto," Biolinguistics 1 (2007): 1-8, on the strong/ weak senses of biolinguistics.
16. Noam Chomsky, Language and Problems of Knowledge: The Managua Lectures (Cambridge, MA: MIT Press, 1988), 2-3.

17. Noam Chomsky, "The Galilean Challenge: Architecture and Evolution of Language," Journal of Physics: Conference Series 880 (2017): 3, doi:10.1088/1742-6596/880/1/012015.

18. E.g., Noam Chomsky, Language and Mind (New York: Harcourt, Brace \& World, 1968; Cambridge: Cambridge University Press, 2006).

19. Chomsky, Language and Problems of Knowledge, 62-63.

20. Chomsky, Language and Problems of Knowledge, 73.

21. Chomsky, Language and Problems of Knowledge, 149.

22. For recent critical reflections, see also Sławomir Wacewicz et al., "Language in Language Evolution Research: In Defense of a Pluralistic View," Biolinguistics 14 (forthcoming).

23. Noam Chomsky, Essays on Form and Interpretation (Amsterdam: North-Holland, 1977), 207.

24. Noam Chomsky, Lectures on Government and Binding (Dordrecht: Foris, 1981), 3.

25. Chomsky, Language and Problems of Knowledge, 91.

26. Chomsky, Language and Problems of Knowledge, 101.

27. Grohmann and Kambanaros, "Foundational Issues in Biolinguistics."

28. I expand on this point in my reply to the letter to the editors authored by Fahad Rashed Al-Mutairi.

29. Scott Lilienfeld et al., "Fifty Psychological and Psychiatric Terms to Avoid: A List of Inaccurate, Misleading, Misused, Ambiguous, and Logically Confused Words and Phrases," Frontiers in Psychology 6 (2015): 1,100, doi:10.3389/ fpsyg.2015.01100. 